\title{
Microstructure profile on selected-traditional Indonesian herbal powder
}

\author{
Naqiyah A. Mulachelah ${ }^{1}$, Syahputra Wibowo ${ }^{2}$, Sri Widyarti ${ }^{3}$, Sutiman B. Sumitro ${ }^{3 *}$
}

\begin{abstract}
${ }^{1}$ Master Program, Department of Biology, Faculty of Mathematics and Natural Sciences, Universitas Brawijaya, Malang, Indonesia 65145
${ }^{2}$ Doctoral Program, Department of Biology, Faculty of Mathematics and Natural Sciences, Universitas Brawijaya, Malang, Indonesia 65145 ${ }^{2}$ Department of Biology, Faculty of Mathematics and Natural Sciences, Universitas Brawijaya, Malang, Indonesia 65145
\end{abstract}

\begin{abstract}
Jamu is well known as traditional herbal medicine that has been used by Indonesian for centuries ago. Local people usually consume jamu for maintaining health and therapy diseases because it is cheaper and has less side effects. Scientific approach needs to be done to study the characteristic of the herbals. This research aims to characterize Indonesian herbal medicine based on microstructure using Scanning Electron Microscope (SEM). The samples for this research are rosela flower (Hibiscus sabdariffa), ginger (Zingiber officinale), lime fruit (Citrus aurantifolia), and celebes pepper (Piper crocatum). The infusion method preparation was carried out. The mixture was processed further by a freeze-drying method to obtain a powder form. SEM was utilized to capture the herbal powder image. Size of distribution and surface roughness were analysed by ImageJ and Origin Pro 8 on SEM images. The size measurement result showed that infused Rosella has the biggest grain $(53.5 \mu \mathrm{m})$, followed by lime $(43.8 \mu \mathrm{m})$, ginger $(41.2 \mu \mathrm{m})$ and celebes pepper $(38.4 \mu \mathrm{m})$. The surface roughness results showed that the roughest samples of all is ginger $(\mathrm{Ra}=64.417)$, followed by lime $(\mathrm{Ra}=$ 58.761), celebes pepper $(\mathrm{Ra}=43.589)$, and rosella $(\mathrm{Ra}=30.855)$. In conclusion, based on its size measurement result, celebes pepper is the most soluble and has the highest bioavailability, followed by ginger, lime, and rosella. According to its surface roughness, celebes pepper also showed the most soluble compared to other samples, followed by lime, ginger and rosella.
\end{abstract}

Keywords: infusion, jamu, SEM, size distribution, surface roughness

Received: December 21, 2021 Revised: February 08, 2022 Accepted: February 10, 2022

\section{Introduction}

Plants as a medicine to treat human disease is a historically known knowledge, especially by Indonesian. Almost all medicine preparation back then was using plants (Husein et al., 2019). The knowledge of the use of medicinal plants has been passed on orally generation after generation on their tribes, and even outside their tribes (Jadid et al., 2020). Its ubiquitous usages are attributed to its cheap price and relatively weak side effects (Husein et al., 2019). Rosela flower (Hibiscus sabdariffa), ginger (Zingiber officinale), lime (Citrus aurantifolia), and celebes pepper (Piper crocatum) are common herbal medicines. Rosella flower is used for preventing cancer and lowering pressure (Dewantari, 2018). Ginger is usually used for respiratory nose, ear, oral/dental, throat problems, cough (Jadid et al., 2020), venomous snake-bite, asthma, headache, stomachache, back pain, influenza, maintaining the immune system (Hijrah et al., 2019), body warmer (Elfrida, 2021), antiemetic, rheumatism, anorexia, cholera, influenza, anemia, malaria, anthelmintic, cough and vertigo (Elfahmi et al., 2014). Lime is usually used for cough (Elfrida, 2021), tonsillitis, cough with phlegm, fever, headache, hemorrhoid (Hijrah et al., 2019), and adding herbal flavor (Husein et al., 2019). Celebes pepper is

\footnotetext{
Corresponding Author:

Sutiman Bambang Sumitro

Department of Biology, Faculty of Mathematics and Natural

Sciences, Universitas Brawijaya, Malang, Indonesia 65145

Phone: +6281233068579

E-mail: sutiman@ub.ac.id
}

used for nosebleed (Elfrida, 2021), sprue, cough, acnes, and tonea vascolor (Dewantari, 2018).

Herbal medicine can be prepared by several methods. The sample uses the whole part of the plants or any part of it. The preparation consists of certain methods, such as infusion, percolation, decoction, digestion and Soxhlet extraction, ultrasound-assisted, superficial extraction, and microwave-assisted extraction (Haque, 2020). For this research, the preparation method used the infusion method. The infusion method is one of the simple methods also known as maceration. The dried plant is ground into a powder, then immersed in an extraction solvent (hot or cold) (Haque, 2020). Since the infusion preparation process is done by dissolving the herbal materials into a liquid solvent, the sample is likely to have a small particle size. Only the herbal material particle that is small enough will dissolve into the solvent Small particle sized material tends to have faster intrinsic dissolution rate (Bynum et al., 2011). This is why size measure analysis is also performed in this research. By reducing the particle size, the solubility and bioavailability can be increased. Surface roughness analysis is also performed. Surface roughness provides data for measuring surface area character based on surface topography. A sample with a rougher surface means it has a wider surface area (Lim et al., 2013). From a solubility perspective, a wide surface area means more parts that can interact with the solvent. Therefore, rougher the surface means more soluble properties.

Both size measure and surface roughness analysis demonstrate the quality of the jamu powder. In the future, it is expected that these analyses can utilize for 
determining the quality of the jamu powder. The purpose of this research is to elucidate the scientific value of herbal preparations by characterization based on microstructural profiles using SEM (Scanning Electron microscope).

\section{Methods}

\section{Sample preparation}

The dried plants were obtained from UPT Laboratorium Herbal Materia Medica Batu, East Java, Indonesia. The samples and the plants' parts that were used for this research can be seen in Table 1. Its powder form was then sifted with a 200 mesh sieve. One mg of the powder was mixed with $20 \mathrm{ml}$ of aquadest and stirred for 24 hours. After freeze-dried, obtained-powder grain of infused-herbs was proceeded for SEM analysis.

Table 1. Herbal samples

\begin{tabular}{cc}
\hline Herbs & Parts of Herbs \\
\hline Ginger (Zingiber officinale) & Rhizome \\
Rosella (Hibiscus sabdariffa) & Flower \\
Lime (Citrus aurantifolia) & Rind \\
Celebes pepper (Piper crocatum) & Leaf \\
\hline
\end{tabular}

\section{Sample analysis}

\section{Scanning electron microscope}

For SEM observation, the samples in powder form (after freeze-drying process) were mounted on double sided conductive carbon adhesive tape without any sputtering. The specimens were visualized under Field Emission Scanning Electron Microscope (FESEM) (SEM

\section{Results}

\section{Size distribution}

The SEM image shows a whole outlook of each sample bulks under a microscope per $500 \mu \mathrm{m}$ area (Fig. 1). The item of grains taken for size measurement sampling are marked as region of interest (ROI). The grain criteria taken for ROI must be grains that look intact, without any part being covered by other samples or cut off by the edges of the image. Those grains are calculated by their area. The result is calculated further for mean and standard deviation value.

Since every sample has a different number of grains, the amount of ROI taken for each sample is also different. For ginger, 63 grains were taken for sampling. Meanwhile, the sampling taken for lime, rosella, and celebes pepper flowers consecutively are 40,21, and 35 grains. The standard deviation of each sample is high because the size distribution is widely spread. A histogram containing the frequency distribution of each sample supports this explanation (Fig. 1). Every sample has its scale of frequency shown on the graph.

While ginger, lime, and celebes pepper sized below $44 \mu \mathrm{m}$ range, rosella mean size reaches more than $63 \mu \mathrm{m}$. The average size of ginger is about $41.2 \mu \mathrm{m}$ (Fig. 2). This followed by 19.5 values of standard deviation. The high standard deviation value indicates that the sample mean size result is not well distributed. This result corresponds to the SEM image and the size distribution graph (Fig. 1a).
FEI Quanta FEG 650 at Laboratorium Sentral Ilmu Hayati, Brawijaya University, Malang). It was performed in $60 \mathrm{x}$ magnification, $10 \mathrm{~mm}$ working distance, $10 \mathrm{kV}$ voltage, $80 \mathrm{~Pa}$, and LFD for SE (secondary electron) detector. All of the SEM images were then processed further for grain size measurement and roughness analysis using software.

\section{Image $J$ analysis}

ImageJ (National Institutes of Health and the Laboratory for Optical and Computational Instrumentation (LOCI, University of Wisconsin)) was used for analyzing the overview of SEM images. A straight line in the ruler of the image was used as the basis for setting a size scale for measurement. The 'known distance' box was filled with the unit length based on the information in the image. Region of interest (ROI) analysis was used to get the average size of each object in the image. ROI selection used freehand selection tools. ImageJ software was used to calculate the wideness of the 2D area of each grain in the SEM image. After the area calculation of each grain was obtained, the diameter was calculated based on these data. Then, the average was calculated along with the standard deviation using OriginPro (OriginLab Corporation, Northampton, MA 01060 USA). The histogram of the size distribution was also made by OriginPro software. Furthermore, for surface roughness data, the "SurfCharJ 1q" plugins were used to obtain information about the sample surface roughness of each image.
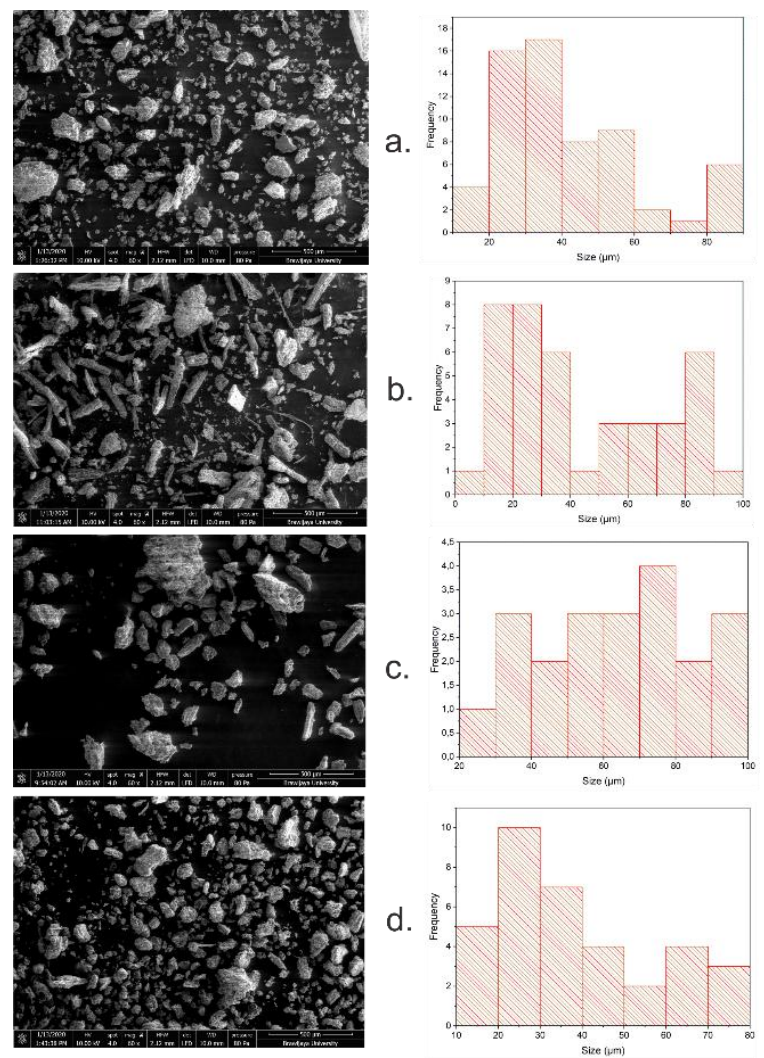

Figure 1. SEM image result (left) and its size distribution (right) of (a) ginger, (b) lime, (c) rosella, (d) celebes pepper. 
Among the samples that were taken for sampling, the size looks highly distinctive. This explains the obtained high standard deviation. The graph shows the summary of the measurement. About 34 grains of the sample have sizes ranging around $20-40 \mu \mathrm{m}$. Seventeen grains are sized around $40-60 \mu \mathrm{m}$, while the rest is about $60-80 \mu \mathrm{m}$.

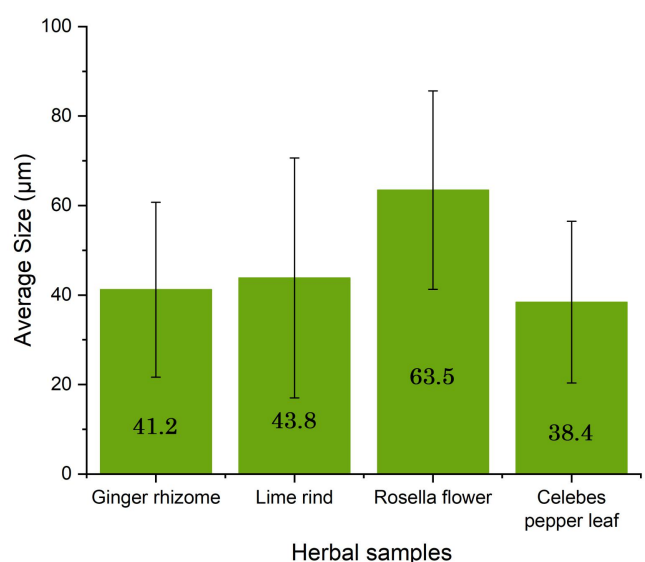

Figure 2. Average size of the samples

The average size distribution of lime is about 43.8 $\mu \mathrm{m}$. This followed by 26.8 value of standard deviation. Like ginger, the grain sizes of the lime are various. Over 40 grains that were taken for sampling, some of grain powder shaped long, and some of them shaped round. Some of it also looks big, some of it looks small. The size distribution graph (Fig. 1b) shows that 25 grains were sized below $40 \mu \mathrm{m}$. The rest were sized around 40$100 \mu \mathrm{m}$.

The average size distribution of rosella is about 63.5 $\mu \mathrm{m}$. This followed by 22.2 values of standard deviation. Compared to the other samples, rosella average size is the highest. It consisted of a round and tube-like shape. There are a total 21 grains of powder that were taken for sampling. Among all of it, the size variations are not as varied as other samples. This explains the relatively low standard deviation (compared with other samples). The frequency of the samples that found on every size range are almost identical (Fig. 1c). The samples ranged below $100 \mu \mathrm{m}$.

Based on the size distribution graph of celebes pepper, we can know that the grains are dominantly sized under $30 \mu \mathrm{m}$. Plenty of samples are sized on $30-40 \mu \mathrm{m}$ range, while few of the rest were ranged until $80 \mu \mathrm{m}$. The average size distribution of celebes pepper is about 38.5 $\mu \mathrm{m}$. This is followed by 18.1 values of standard deviation. Compared with other size measurement results, celebes pepper has the smallest grain size of all.

Sample preparation in this study used the infusion method. This method is done by dissolving the powder sample in water. Based on Shekonov at al. (2006) the common issues to withdraw the smallest quantity of the bulk material are usually due to particle segregation or insufficient sampling weight. Percolation among coarse and fine particle fractions or agglomeration between different types of multicomponent mixtures can cause segregation. In suspensions sample, sedimentation of particle and concentration gradients can play a role in selective sampling. Constructing sample from a great number and/or mixing of increments can minimize these issues.

\section{Surface roughness}

Surface roughness is height variations of the surface that is dependent on a plane reference. The measurement can be either by a single line profile or by a set of parallel line profiles (surface maps). Few statistical height descriptors are usually used for its characterization (Bhusan, 2021). For understanding the homogeneity of the surface, a local roughness analysis was performed. The sample with a rough surface has a low surface area. Lower surface area means the lower the solubility (Lim et al., 2013). The components that are used for surface roughness analysis consideration (based on Profile Parameters from ISO 4287) are Rp (highest peak), Rv (lowest valley), Rt (total roughness), Rq (rootmean-squared deviation roughness), and Ra (Arithmetic mean roughness).

\begin{tabular}{|c|c|c|c|c|}
\hline & Ginger & Rosella & Lime & Celebes Pepper \\
\hline $\mathrm{Rq}$ & 89.205 & 58.855 & 84.416 & 74.518 \\
\hline $\mathrm{Ra}$ & 64.417 & 30.855 & 58.761 & 43.589 \\
\hline
\end{tabular}

$\mathrm{Rp}$ value represents the maximum height of the peak. It values the elevation of the highest peak according to the mean line, fixed on the sampling width (Bhusan, 2021). Based on the measurement, all of the sample pictures have the same peak, which is 255 . On the other hand, $\mathrm{Rv}$ value shows the maximum depth of the valley profile. It shows the length of the deepest valley from the mean line, based on the sampling length (Bhusan, 2021). The Rv value of the samples are all the same, 0 .

Rt value shows the total height of the profile. It explains the evaluation length, since it is obtained from the measurement of the total length between the lowest valley and the highest peak. Since the value of the highest and the lowest is the same between the samples, the Rt value is also the same between the samples.

$$
\mathrm{Rt}=\mathrm{Rp}-\mathrm{Rv}=255-0=255
$$

The surface roughness of the sample can be determined from the pixel value of the image. The detector that is used for capturing the SEM image in this research is an LFD detector. This detector allows secondary electrons detection. Therefore, the obtained SEM image tells about the topography of the sample. The black and white color spectrum in the image demonstrates the surface's height. In the picture, brighter (closer to white) is interpreted as a higher peak. The darker (closer to black) is interpreted as a deeper valley. Analysis of imageJ data using origin pro produces data about the mean of these peaks and valleys. The area of the mean deviation is also obtained, which is called the arithmetical mean deviation ( $\mathrm{Ra})$. Visualization of the $\mathrm{Ra}$ value can be seen from Figure 3. 


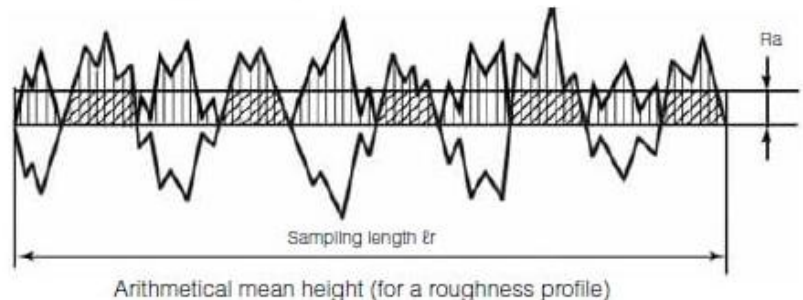

Figure 3. Visualisation of Ra value (https://www.keyence.com/ss/ products/microscope/roughness/line/parameters.jsp)

If a sample has high peaks and/or low valleys, the Ra value will be high as well. Samples that have high peaks and low valleys mean the surface is rough. Therefore, a high Ra value can be used as an indicator that the surface is rough, vice versa. The research data showed that $\mathrm{Ra}$ of the ginger is 64.417 , rosella is 30.855 , lime is 58.761 and celebes pepper is 43.589 .

Meanwhile, when the $\mathrm{Ra}$ value is squared, a rootmean-squared deviation or $\mathrm{Rq}$ is obtained. $\mathrm{Rq}$ interprets the standard deviation of the distributed height, defined on the sampling length (Chinga, 2007). To confirm the value of the deviation throughout all the peaks and valleys, $\mathrm{Rq}$ number is calculated. The lowest $\mathrm{Rq}$ value is obtained by Rosella, which is 58.855 . The highest $\mathrm{Rq}$ value is obtained by Ginger, which is 89.205 .

\section{Discussion}

For size distribution data, the high standard deviations are still acceptable since the sizes are not uniform. All the SEM pictures demonstrate that the size and form of the grains vary. The obtained average size shall explain the dominance size, instead of the all exact obtained size in the scene. The distribution of the size in every sample can be seen on the graphs (Fig. 1).

The usual method to analyse roughness is using instruments such as digital surface roughness tester. However, this research uses a distinct approach to obtain roughness data. Instead of using instrument to get its calculation, this research method uses images pixel to calculate the roughness value. SEM images that tells the topography of the sample can be "pixelly quantified" to get the calculation. The software for the image analysis is imageJ. Moreover, aside of imageJ, a paper by Grandi et al. (2020) demonstrates another software alternative to analyse surface roughness, such as MeX.

In the surface roughness measurement, the $\mathrm{Rp}$ value shows the highest peak of the sample, which is the "whitest" pixel of the image. Rv value shows the lowest peak of the sample, which is the "black-est" pixel of the sample. Among both of the values, the mean line can be obtained as a zero point of the graph. Rp value shows the maximum number, while the Rv value shows the minimum number (Chinga, 2007). Both values serve a purpose as the baseline of the measurement. Together, the range of the measurement can be known. All the sample images must have the same value of $\mathrm{Rp}$ and $\mathrm{Rv}$ to be compared. Thus, the pixel length of every image is precisely equivalent. This research data shows the Rp and $\mathrm{Rv}$ of all samples are the same. Therefore, the surface roughness calculations of the samples are valid to be compared.

Ra value can be obtained by measuring the average of the absolute values of the profile height deviations from the mean line, accounted within the evaluation length. Ra value demonstrates how rough the sample surface is (Chinga, 2007). These results demonstrate that ginger has the roughest surface compared with other samples, followed by lime, celebes pepper, and rosella. A rougher surface means more surface area, reciprocally indicating a higher solubility because there is more area to interact with the solvent (Lim et al., 2013). The ginger rhizome has the highest solubility compared with other samples, followed by lime rind, rosella flower, and celebes pepper leaf.

However, in order to calculate surface roughness correctly, it is necessary to use an image that shows the entire grain surface in a single field of view. In this research, the SEM image captured views that show many grains (instead of only one) in one field of view. There is a drawback of using an image with this feature. If the sample grains do not cover all surfaces, the background of the image will be accounted into the surface roughness calculation by the automatic computer algorithm of the pixel processor. As a result, the obtained value becomes less valid because the non-sample area is included in the calculation data. This concept may explain why the $\mathrm{Ra}$ value of the Rosella is low (table 1). It is because there is more background to add to the measurement.

Nevertheless, this method can be perfectly applied under circumstances, such as: all field view of the image is the surface of the sample and the SEM image tells the topography of the sample. In the future, capturing the SEM images of the sample for surface roughness analysis should be done with an all-surface field of view. The overview images that shows many grains of the sample should only be used for size distribution analysis. Meanwhile for surface roughness analysis, it should be zoomed in into a grain of the sample that shows its surface.

Aside of the field of view the sample, another thing to consider is the detector of that is used for capturing the SEM image. SEM detectors collect the signal generated from the interaction of electron beam with the specimen. Electronic detectors convert the signal into digital images. Three types of SEM detectors are secondary electron detector (Everhart-Thornley), backscattered electrons detector (Solid-State detector) and Energy dispersive spectrometer (EDS) detector. The type of detector to use for a purpose of analysis surface roughness is a Secondary Electron (SE) detector. Secondary Electron detector produces image that tells information about surface topography of the object. The surface features or "how it looks" can be "imaged", along with its texture (Kannan, 2018).

Ultimately, although this method is promising, more technical properties should be concerned carefully. This method using imageJ can be an alternative to measure surface roughness. However, due to grain size being measured in this research, it would be better if particle size analyzer (PSA) is also used. This instrument will be helpful to support the grain size data. A research by Li et 
al. (2021) proved that dry dispersion of Chinese medicine powder that is analyzed by laser diffraction particle size analyzer can provide high precision particle size distribution result. In the future, combining both ImageJ software and PSA analysis will produce a more reliable size distribution data.

In conclusion, the evaluation of SEM profile pictures signifies that the smallest grain size among the samples

\section{Acknowledgments}

This research is funded by Hibah Penelitian Guru Besar FY 2020/2021 Brawijaya University.

\section{References}

Abubakar AR, Haque, M. 2020. Preparation of medicinal plants: Basic extraction and fractionation procedures for experimental purposes. J Pharm Bioall Sci 12:1-10

Bhusan, Bharat. 2001. Surface Roughness Analysis and Measurement Techniques. Ohio: CRC Press LLC.

Bynum, K. C. 2011. Preformulation and early phase method development. Separation Science and Technology, 361-396.

Chinga, G., Johnssen, P.O., Dougherty, R, Lunden-Berli, E. and Walter, J. 2007. Quantification of the 3-D micro-structure of SC surfaces. J. Microscopy 227 (3): 254-265.

Dewantari, R., L, Monika L, \& Nurmiyati. 2018. Jenis Tumbuhan yang Digunakan sebagai Obat Tradisional Di Daerah EksKaresidenan Surakarta. Bioedukasi 11(22): 118-123

Elfahmi, Woerdenbag, H. J. \& Kayser, O. 2014. Jamu: Indonesian traditional herbal medicine towards rational phytopharmacological use. J. Herb. Med. 4, 51-73.

Elfrida, Tarigan, N. S. \& Suwardi, A. B. 2021. Ethnobotanical study of medicinal plants used by community in Jambur Labu village, East Aceh, Indonesia. Biodiversitas 22, 2893-2900.

Grandi, G., Timò, A., Sammarini, M., Del Savio, M. C., \& Facchinetti, F. 2020. Surface roughness of different contraceptive vaginal rings: evaluation by scanning electron microscope (SEM). The European Journal of Contraception \& Reproductive Health Care, 25(1), 60-64

Hijrah, Nugrahahani, A.W., Ramdanil. 2019. Studi Etnobotani Tumbuhan Berkhasiat Obat Pada Suku Tau Taa Wana Di Desa is ginger, while the biggest one is rosella. The surface roughness analysis shows that ginger has the roughest surface of all, while rosella is the smoothest. This research also demonstrates that analysing surface roughness can also performed from SEM image using imageJ. This imaging process using software is an alternative that can be helpful.

Bulan Jaya Kecamatan Ampana Tete, Kabupaten Tojo Una Una, Provinsi Sulawesi Tengah. Biocelebes 13(1): 76-86 http://jurnal.untad.ac.id/jurnal/index.php/Biocelebes/article/view $/ 12876$

Husain, F., Wahidah, B.F., Prasetyo, K.B., Massholeh, M.A. 2019. Traditional Knowledge of Medicinal Plants among Sellers of Jamu Gendong in Wonolopo, Indonesia. ICEL, Malang, Indonesia. EAI.

Jadid N, Kurniawan E, Himayani CES, Andriyani, Prasetyowati I, Purwani $\mathrm{Kl}$ et al. 2020. An ethnobotanical study of medicinal plants used by the Tengger tribe in Ngadisari village, Indonesia. PLoS One 15, 1-16.

Kannan, M. 2018. A Textbook on Fundamentals and Applications of Nanotechnology. Daya Publishing House: A Division of Astral International Pvt. Ltd (pp.81-92). New Delhi

Keyence. 2021. Surface Roughness Parameters. Retrivied from https://www.keyence.com/ss/products/microscope/roughness/lin e/parameters.jsp

Li, Xuebing, Liu, Shiqi, Li, Mei \& Xu, Liyang. 2021. Research on Particle Size Measurement of Chinese Medicine Powder by Laser Particle Size Analyzer. Bettersize Instruments Ltd. Retrivied from https://www.bettersizeinstruments.com/learn/ research-on-particle-size-measurement-of-chinese-m.html

Lim, J. D., Susan, Y. S. Y., Daniel, R. M., Leong, K. C., \& Wong, C. C. 2013. Surface roughness effect on copper-alumina adhesion. Microelectronics Reliability, 53(9-11), 1548-1552.

Roshetko, J. M., Purnomosidhi, P., Sabastian, G., Dahlia, L., Mahrizal, M., Mulyoutami, E., \& Martini, E. 2017. Ethnobotanical use and commercial potential of Moringa oleifera in Indonesia: an underused and under-recognized species. Acta Horticulturae 1158:349-356. 